\title{
Leadership beyond Narcissism: On the Role of Compassionate Love as Individual Antecedent of Servant Leadership
}

\author{
Tim Brouns ${ }^{1, *(\mathbb{D}, \text { Kai Externbrink }}{ }^{2}$ and Pablo Salvador Blesa Aledo ${ }^{1}$ \\ 1 Economía y Empresa, UCAM Universidad Católica San Antonio de Murcia, 30107 Murcia, Spain; \\ pblesa@ucam.edu \\ 2 Economics and Management, FOM University of Applied Sciences, 45127 Essen, Germany; \\ kai.externbrink@fom.de \\ * Correspondence: tim.brouns@t-online.de
}

Received: 6 February 2020; Accepted: 23 March 2020; Published: 26 March 2020

\begin{abstract}
While we already know a lot about the outcomes and boundary conditions of servant leadership, there is still a need for research on its antecedents. Building on the theory of purposeful work behavior and further theorizing by van Dierendonck and Patterson (2015), we examine if leaders' propensity for compassionate love will evoke servant leadership behavior. At the same time, we contrast compassionate love to leaders' narcissism as psychological counterpart to compassionate love, because narcissism is not associated with leader effectiveness, but with leader emergence instead. We collected data from 170 leader-follower-dyads in a field study in Germany, while measuring leaders' compassionate love and narcissism, and followers' perceptions of servant leadership. We found a positive association between leaders' compassionate love and servant leadership behavior, while narcissism was negatively associated with servant leadership. Theoretical and practical implications, as well as pathways for future research are discussed.
\end{abstract}

Keywords: servant leadership; compassionate love; narcissism; antecedents

\section{Introduction}

Inspired by Greenleaf's seminal essays, empirical research using psychometrically sound measures has profoundly advanced our view on servant leadership. Current empirical evidence suggests its beneficial effects on follower performance and organizational citizenship behavior (OCB), beyond transformational leadership and leader-member-exchange (LMX), across different jobs and cultures (e.g., Liden et al. 2008; Van Dierendonck and Nuijten 2011; Sendjaya et al. 2008).

Eva et al. (2019) reviewed the state-of-the-art in servant leadership research. Ample research on the measurement, mediators, moderators and outcomes of servant leadership has been carried out. As far as its antecedents and role in stimulating servant leadership are concerned, however, there is still great potential for further research. In their systematic review, they analyzed a total of 11 empirical studies which focused on leaders' traits as precursor of servant leadership: high agreeable, low extraverted individuals (Hunter et al. 2013), who are self-confident (Flynn et al. 2016) and mindful (Verdorfer 2016), tend to act as servant leaders.

These findings contradict, at least in part, the literature on leadership emergence, which states that especially narcissistic personalities tend to emerge faster into leadership positions (e.g., Externbrink and Keil 2018). At the same time, narcissism is a limitation on leadership success, i.e. the effectiveness of a leader. Emergence in leadership roles is achieved by narcissistic personalities through an ambitious, visionary and charismatic appearance, supported by very good rhetorical skills, which allows them 
to achieve an impression of "charming at first sight" (Grijalva et al. 2015). This rise into a leadership role is accompanied by disadvantages in terms of leadership effectiveness, in that employees are not valued, and rash and risky decisions are made (ibid.). In addition, narcissists are not receptive to criticism and tend to throw tantrums (cf. Campbell et al. 2002). Narcissistic leaders love themselves abundantly resulting in the problem of insufficient leadership effectiveness. Other studies rather suggest that the psychological counterpart of narcissism, namely humility or compassionate love, is a suitable antecedent for effective leadership like servant leadership (Van Dierendonck and Patterson 2015). To capture the two poles of the continuum between leading with abundant self-love and leading with love towards non-intimate others, both narcissism and compassionate love are examined here as antecedents of servant leadership.

Brouns (2019) has argued that personal antecedents of servant leadership can be studied in depth by referring to the Theory of Purposeful Work Behavior (Barrick et al. 2013). The core principle of the theory is that individual characteristics initiate purposeful goal strivings, and when certain job characteristics act in concert with these purposeful motivational strivings, individuals perceive a psychological state of experienced meaningfulness, which in turn triggers task-specific motivation and coherent work behavior.

The aim of this study is to assess compassionate love and narcissism as antecedents of servant leadership. Here, we propose that individuals displaying a high degree of compassionate love will perceive a higher purpose in striving for communion and, once promoted to leadership positions, will engage in servant leadership behaviors in line with their prosocial motivation. To further develop this theoretical line of argument we also incorporate the theorizing of Van Dierendonck and Patterson (2015) which is based on virtue theory. In contrast, we assume that narcissistic leaders do not show servant leadership, because they do not strive for social affiliation, but have a very strong self-relation and are the psychological antithesis of leaders who show compassionate love towards their employees.

Compassionate love refers to love that "centers on the good of the other" (Underwood 2008, p. 3) and ultimately mirrors the "servant-first approach" to leadership as already proposed in early conceptualizations of servant leadership (Greenleaf 1977):

The Servant-Leader is servant first. [...] It begins with the natural feeling that one wants to serve, to serve first. Then conscious choice brings one to aspire to lead. [...] The best test, and difficult to administer is this: Do those served grow as persons? Do they, while being served, become healthier, wiser, freer, more autonomous, and more likely themselves to become servants? And, what is the effect on the least privileged in society? Will they benefit, or at least not further be harmed? (p. 7)

Van Dierendonck and Nuijten (2011) distinguished eight key characteristics that are generally quoted as the essential elements of servant leadership and -as we will outline below-hold promising relations to compassionate love: standing back, forgiveness, courage, empowerment, accountability, authenticity, humility, and stewardship. In this line of reasoning, servant leadership can not only theoretically but also empirically be distinguished from other forms of positive leadership: Hoch et al. (2018) for example conducted a meta-analysis comparing authentic, ethical, and servant leadership with transformational leadership in their associations with a wide range of organizationally relevant measures. Their results show that servant leadership has much lower conceptual overlap than the other constructs and also appears as the most promising precursor of a wide range of desirable leadership outcomes.

According to Underwood's framework (Underwood 2008) five key features constitute compassionate love, which include free choice for the other; accurate cognitive understanding of social situations, the other, and oneself; valuing the other at a fundamental level; openness and receptivity; and the response of the heart.

In contrast, narcissism in its subclinical manifestation means that people who have this trait are very self-centered and have a high degree of self-love and a sense of entitlement (Campbell et al. 2002). 
The construct of narcissism is divided into the following three dimensions: Leadership/authority, grandiose exhibitionism and entitlement/exploitativeness (Ackerman et al. 2011).

In the following we will show that compassionate love is an integral part of servant leadership, whereas narcissism, as the psychological opposite of compassionate love, suggests a negative link to servant leadership. Hereby we will contribute to the literature as follows: we will broaden the perspective on antecedents of servant leadership as postulated by Van Dierendonck and Patterson (2015). Both leadership research and leadership practice benefits from such a deeper exploration in terms of leadership selection, assessment and development. A clearer picture of the personality traits and motives of leaders who show servant leadership behavior will gradually close the knowledge gap about which screening criteria companies need to consider when selecting leaders. Through our bilateral approach, compassionate love as the theoretical core and narcissism as the conceptual antithesis of servant leadership, we will provide a framework of what characteristics leaders must offer (compassionate love) and what they should not have (narcissism) in order to be a good, effective leader in terms of servant leadership theory.

\section{Compassionate Love and Servant Leadership}

Love in romantic relationships has been broadly studied in the last decades while love for close others, e.g., friends and family but also all mankind, has not been deeply researched (Sprecher and Fehr 2005). The following definition of compassionate love was offered by Sprecher and Fehr (2005): compassionate love is generally understood as orientation towards others, "either close others or strangers or all of humanity; containing feelings, cognitions, and behaviors that are focused on caring, concern, tenderness, and an orientation toward supporting, helping, and understanding the other(s), particularly when the other(s) is (are) perceived to be suffering or in need" (p. 630). Furthermore, compassionate love is distinct from closely related concepts like empathy, as it is steadier and more comprehensive (Sprecher and Fehr 2005).

This compassion for non-intimate others, e.g., subordinates of a leader, is in line with the ideology of servant leadership. The leader has to show this kind of love for followers to learn much about their personalities and individual differences, strengths, and weaknesses (Van Dierendonck and Patterson 2015). Hence, leaders who have compassionate love for their followers, put followers' talents first and attribute their own and organizational goals a secondary role (ibid.). Compassionate love was described as a practical manifestation of the core principle of servant leadership, the need to serve, concluding that this construct is foundational to exemplify servant leadership behaviors in an organizational context (Greenleaf 1977; Van Dierendonck and Patterson 2015).

Furthermore, Van Dierendonck and Patterson (2015) argued that compassionate love stimulates moral emotions in leaders. Moral emotions are always associated with the welfare or interests of the community or another person, not with oneself (Haidt 2003). This is in line with the original idea of servant leadership and reveals genuine interest in the benefit of others (Greenleaf 1977). Therefore, we propose the following hypothesis.

Hypothesis 1. Leaders' compassionate love towards non-intimate others is positively associated with servant leadership behavior.

\section{Narcissism and Servant Leadership}

Research on narcissism and leadership has a long tradition (e.g., Higgs 2009; Resick et al. 2009). Some years ago, a meta-analysis on this topic was published, which summarized the following results (Grijalva et al. 2015): Leadership was considered from two perspectives, emergence and effectiveness. Narcissistic personalities are more likely to take on leadership roles, which is due to the conceptual overlap between subclinical narcissism and extraversion. Thus, narcissists rise to leadership positions because they are more extraverted. Narcissism showed no linear relationship with leadership 
effectiveness. When leadership effectiveness was collected as a self-report from the leader, there was a significant linear relationship, which supports the assumption that narcissists tend to overestimate their own performance. Instead of a linear effect, a curvilinear effect in an inverted U-shape was found, which means that moderate subclinical narcissism is most conducive to leadership effectiveness.

With reference to the Theory of Purposeful Work Behavior (Barrick et al. 2013) we assume that personality traits of the leader trigger purposeful goal strivings. Already, Hunter et al. (2013) could show that agreeableness was positively, and extraversion negatively related to servant leadership. Since narcissists are generally extraverted, less agreeable personalities (Bradlee and Emmons 1992), it follows from the Theory of Purposeful Work Behavior that their motives are more agentic and less communion oriented (Campbell et al. 2002). Therefore, narcissists are less motivated to exercise an others-oriented leadership style such as servant leadership, which requires strong communion-striving (Brouns 2019), as this is less in line with their personality and motives (Barrick et al. 2013). For this reason, narcissists would feel less meaning and purpose in their leadership role.

Similarly, Peterson et al. (2012) argued that narcissistic personalities are not inclined to subordinate their personal interests to the interests of others. However, this is one of the central theoretical core elements of servant leadership (Liden et al. 2008; Van Dierendonck 2011). Starting from the pervasive self-love typical of narcissists, they reasoned that narcissistic leaders are unwilling to demonstrate key dimensions of servant leadership, such as standing back, forgiveness, and humility (Peterson et al. 2012).

From these two lines of argumentation, we propose the following hypothesis.

Hypothesis 2. Leaders' narcissism is negatively associated with servant leadership behavior.

\section{Method}

\subsection{Participants and Procedure}

We conducted a cross-sectional survey among occupational students of a German university of applied sciences. Participants were recruited via mailings and during lectures. The sample consisted of 170 participants studying for a bachelor's degree parallel to a full-time job. The participants were surveyed by online questionnaires. This study used different rater sources. Compassionate love and narcissism were rated by the leader and servant leadership was rated by an employee of the leader. We have decided that leadership behavior is assessed by an employee, as the correlations between the leader's self-ratings and the employee's ratings are only moderate (Lee and Carpenter 2018). In leadership, the primary issue is how the leadership behavior is perceived by those being led. For this reason, we have opted for ratings by employees, even though the assumption of a self-enhancement bias of the leader was largely refuted (ibid.). Furthermore, we are convinced that self-ratings are appropriate for personality-based constructs such as compassionate love and narcissism (Conway and Lance 2010). Beyond, the research design is less prone to common source issues (Podsakoff et al. 2003; Podsakoff and Organ 1986). The dyads were always in 1:1 relationships between employee and leader, the data are not nested. This implies moreover that the number of participants corresponds to the number of dyads in the sample $(N=170)$. The survey design was implemented bi-directionally: the occupational student could participate regardless of whether he or she occupied a leadershipor employee-role in his or her organization. To generate leader-follower-dyads, the corresponding hyperlink to the leader- or follower-questionnaire was presented dynamically depending on the role of the first participant of the dyad. If a participant in a leadership-role started with the questionnaire, a link to the employee-questionnaire was presented and vice versa. Table 1 shows the descriptive statistics of both leaders and employees in the conducted sample. Leaders $(M=41)$ were older than employees $(\mathrm{M}=28)$ in the sample. Men were predominant in the leader's category while women were prevalent in the employees' category. 
Table 1. Means and standard deviations for both leaders and employees.

\begin{tabular}{ccccc}
\hline Variable & $\boldsymbol{M}$ (Leader) & $S D$ (Leader) & $\boldsymbol{M}$ (Employee) & $S D$ (Employee) \\
\hline Age & 40.51 & 10.64 & 28.12 & 7.10 \\
Gender & 1.58 & 0.50 & 1.29 & 0.45 \\
\hline \multicolumn{5}{c}{ Note. $N=170$. For gender, $1=$ female, $2=$ male. }
\end{tabular}

\subsection{Measures}

\subsubsection{Servant Leadership Survey (SLS)}

We used the Servant Leadership Survey (SLS; Van Dierendonck and Nuijten 2011) which focuses on the virtuous attitudes and behaviors of servant leaders. As the survey was conducted in Germany, the German translation of the SLS was utilized (Verdorfer and Peus 2014). The scale consists of 30 items on a 6-point Likert-scale. The SLS appeared reliable in the study $(\alpha=0.92)$.

\subsubsection{Santa Clara Brief Compassion Scale (SCBCLS)}

Although we have taken the suggestion made by Van Dierendonck and Patterson (2015) to develop a compassionate love scale related to leadership into account, we believe that it is not required for this study. Sprecher and Fehr (2005) have developed the compassionate love scale to measure compassionate love for close others and compassionate love for non-intimate others. These two contexts have been distinguished and have partly shown other correlations in empirical studies. We argue that the leadership context is comparable to the compassionate love for non-intimate others. Even if leader-member-exchange (e.g., Graen and Uhl-Bien 1995) postulates that close relationships between employees and leaders should be established, these are embedded in a professional occupational context and therefore cannot be equated with relationships to close others. Therefore, we used the SCBCLS in this study to measure compassionate love to non-intimate others. This scale is more suitable for this study because compassionate love for non-intimate others is taken into consideration and the questionnaire is very efficient with only 5 items. Those items were measured on a 7-point Likert-scale and showed good reliability with Cronbach's $\alpha=0.84$. All items were back-translated from their original form into German language (Brislin 1970).

\subsubsection{Narcissistic Personality Inventory-13 (G-NPI-13)}

Narcissism was introduced to the study to replicate results on the antecedents of servant leadership. The subclinical personality trait narcissism was measured with the German version of the Narcissistic Personality Inventory-13 (G-NPI-13) by Brailovskaia et al. (2017). The scale consists of 13 items on a 5-point Likert-scale and showed a good reliability with Cronbach's $\alpha=0.79$ and psychometrically performed better than in the validation studies of the G-NPI-13 e.g., Brailovskaia et al. (2017).

\section{Results}

Before testing the hypotheses, we conducted a confirmatory factor analysis (CFA) to examine whether our measures captured distinctive constructs. Since two constructs, narcissism and compassionate love, were surveyed as self-assessments, a CFA was conducted to show discriminant validity between narcissism and compassionate love. Furthermore, a CFA for the SLS construct was performed to check whether the data fit into the measurement model. The CFA analyses were computed with the R package lavaan version 0.6-4 (Rosseel 2012). Furthermore, we performed ordinary least squares (OLS) regression analysis with the R package stats (R Core Team 2019). 


\subsection{Confirmatory Factor Analysis (CFA)}

In CFA, $\chi 2$, comparative fit index (CFI), Tucker-Lewis index (TLI) and root-mean-square error of approximation (RMSEA) are reported as indices of model fit. Models are proper if CFI and TLI are at least 0.90, and RMSEA is 0.08 or lower (Hu and Bentler 1999).

The CFA was applied to ensure discriminant validity between compassionate love and narcissism. For the compassionate love scale a covariation of the items one and two was added to the measurement model. In addition, for the GPI-13 item number seven and nine, due to overlapping content, a covariation between both items in the measurement model was also allowed. The CFA came to the following result: $\chi 2(113)=181.38, \mathrm{RMSEA}=0.06, \mathrm{CFI}=0.92, \mathrm{TLI}=0.91$. As all indices have met the cut-off criteria, we assume that the model has proper fit and both constructs have sufficient discriminant validity.

Furthermore, we performed a CFA for the measurement model of servant leadership, rated by the corresponding employee of the leader. Results showed that the accountability dimension of the SLS had to be removed from the measure as the factor loading on the servant leadership construct was very low (0.12) and the $\chi 2$-difference test was significantly lower $(\Delta \times 2=15.20 *)$. Additionally, due to high cross-loadings of item 19, this item was removed from the analysis. Furthermore, due to similarities in the item-wording, a covariation of the SLS-items five and six, as well as 24 and 25 was added. The CFA of the servant leadership construct came to the following result: $\chi 2(290)=461.52$, RMSEA $=0.06$, $\mathrm{CFI}=0.93, \mathrm{TLI}=0.92$. After minor optimizations of the measurement model for servant leadership described above, the fit indices showed good results.

\subsection{Descriptive Statistics and Intercorrelations}

Table 2 shows that leaders' self-assessment of compassionate love was positively correlated to their servant leadership behavior as perceived by their employees. Consistent with past research results, narcissism was negatively associated with servant leadership (c.f. Liden et al. 2014).

Table 2. Means, standard deviations, and correlations with confidence intervals.

\begin{tabular}{ccccc}
\hline Variable & $\boldsymbol{M}$ & SD & $\mathbf{1}$ & $\mathbf{2}$ \\
\hline 1. Compassionate Love & 4.93 & 1.02 & & \\
2. Narcissism & 3.06 & 0.54 & -0.22 & \\
3. Servant Leadership & 4.56 & 0.78 & $0.32 * *$ & $-0.18^{*}$ \\
\hline
\end{tabular}

Note. $N=170 . M$ and $S D$ are used to represent mean and standard deviation, respectively; ${ }^{*}$ indicates $p<0.05$. ** indicates $p<0.01$.

\subsection{Hypotheses Testing}

Both hypotheses were tested using OLS regression analysis. Table 3 shows the results of the regression analysis of compassionate love and servant leadership as criterion. The regression weight was $\beta=0.32(p<0.001)$ with $R^{2}=0.105(p<0.001)$. This result supports the first hypothesis that compassionate love is significantly positively associated with servant leadership.

Table 3. Regression results for compassionate love using servant leadership as criterion.

\begin{tabular}{cccccc}
\hline Predictor & $\boldsymbol{b}$ & beta & $s r^{2}$ & $\boldsymbol{r}$ & Fit \\
\hline (Intercept) & $3.33^{* *}$ & & & & \\
Compassionate Love & $0.25^{* *}$ & 0.32 & 0.10 & $0.32^{* *}$ & $\mathrm{R}^{2}=0.105^{* *}$ \\
\hline
\end{tabular}

Note. A significant $b$-weight indicates the beta-weight and semi-partial correlation are also significant. $b$ represents unstandardized regression weights. beta indicates the standardized regression weights. sr 2 represents the semi-partial correlation squared. $r$ represents the zero-order correlation. ${ }^{*}$ indicates $p<0.05$. ${ }^{* *}$ indicates $p<0.01$. 
Table 4 shows the results of the regression analysis of narcissism and servant leadership as criterion. The regression weight was $\beta=-0.18(p=0.017)$ with an $R^{2}=0.033(p=0.017)$. This result supports the second hypothesis that narcissism is significantly negatively associated with servant leadership.

Table 4. Regression results for narcissism using servant leadership as criterion.

\begin{tabular}{lccccc}
\hline Predictor & $\boldsymbol{b}$ & beta & $\boldsymbol{s r}^{2}$ & $\boldsymbol{r}$ & Fit \\
\hline (Intercept) & $5.37^{* *}$ & & & & \\
Narcissism & $-0.27^{*}$ & -0.18 & 0.03 & $-0.18^{*}$ & \\
& & & & & $\mathrm{R}^{2}=0.033^{*}$ \\
\hline
\end{tabular}

Note. A significant $b$-weight indicates the beta-weight and semi-partial correlation are also significant. $b$ represents unstandardized regression weights. beta indicates the standardized regression weights. $s r 2$ represents the semi-partial correlation squared. $r$ represents the zero-order correlation. ${ }^{*}$ indicates $p<0.05$. ${ }^{* *}$ indicates $p<0.01$.

In summary, both results of the regression analyses confirm the theoretically derived hypotheses. Significant regression weights were found for both compassionate love $(\beta=0.32, p<0.001)$ and narcissism $(\beta=-0.18, p=0.017)$. The results of the statistical analysis are discussed below.

\section{Discussion}

First and foremost, the general association of compassionate love and servant leadership as proposed by Van Dierendonck and Patterson (2015) was tested with regression analysis. In addition, narcissism, a subclinical form of self-love and argued as counter concept to compassionate love, was tested as an antecedent of servant leadership. The suspected negative relationship was supported by the results of OLS regression. Moreover, the link between narcissism and servant leadership had a replicative character, since Peterson et al. (2012) had already investigated narcissism in CEOs as a predictor of servant leadership. The results of the studies suggest that servant leadership is about leading with love for non-intimate others (employees) and not with exaggerated self-love. The latter has rather the opposite effect, namely to show less servant leadership behavior, which may not be desirable in terms of positive outcomes for employees and leaders, since servant leadership is associated with clear advantages on different levels (Eva et al. 2019).

From a practitioner point of view, our study suggests that individuals who display compassionate love have the potential to be "good" servant leaders who promote the sustainability of the organization in terms of value-driven decisions and positive societal impact. Moreover, they promote healthy and motivated employees. Although this may seem intuitive for leadership researchers, the question remains unanswered whether this also fits into the implicit theories of leaders and human resources management practitioners, e.g., Wienert (1984). Servant leadership is oftentimes rather criticized as a type of social romanticism, instead.

This raises the question of how the acceptability towards such ideas can be encouraged among practitioners. Scientific evidence alone does not suffice as many managers consider it inapplicable, not credible, too complicated or uncomfortable (Briner et al. 2009; Externbrink and Dormann 2015). In our view, organizations should consider ways and means to make servant leadership ideas accessible to leaders. As shown in our work, this could result in fundamental changes to the selection, training and development of current and future leaders within organizations.

Servant leaders are next-generation leaders who show lower obedience to authority, demand authenticity and explicitly advocate for others. In their leadership style, they may find satisfaction and experience meaning. How this can be linked to another common criticism according to which servant leadership increases leaders' perceived stress and strain warrants further research. Rather, we assume that individuals who show compassionate love experience self-concordance through the practice of servant leadership. Hence, those individuals benefit more from their own altruism than people whose personality traits do not fit this style of leadership and view servant leadership more 
in terms of social engineering, as can be seen in our work, for example represented in the negative correlation to narcissism.

This study gives first empirical support for the theory proposed by Van Dierendonck and Patterson (2015) that compassionate love is a cornerstone of servant leadership. The theoretical concept of the mediation relationship proposed in theory (compassionate love $\diamond$ virtuous attitudes $\diamond$ servant leadership behavior $\diamond$ positive organizational outcomes) implies that the servant leadership construct may be split into two building blocks: (virtuous) attitudes and servant leadership behavior. The attitude-related block comprises humility, forgiveness, and standing back; the behavioral block includes empowerment, authenticity, and stewardship. This second-order structure needs to be empirically substantiated in future studies as we used a unitary servant leadership construct.

Moreover, it would be important to see in an overall view of all antecedents so far discussed which variable or combination of variables account for the largest amount of variance in servant leadership. Furthermore, the organizational context or the situation variables that promote servant leadership should be taken into account: here, for example, the ethical organizational climate and hierarchical level are likely to be of particular importance. In our opinion, the interaction of personal and situational determinants may also be particularly conducive to research and may do justice to the servant leadership phenomenon. In their longitudinal study with CEOs, for example, Peterson et al. (2012) showed that a low level of narcissism and the personal founding of a company lead to increased identification with the organization, which in turn increases servant leadership and thus the profitability of a company. Another example for future research could be the consideration of positional and informal power, as research results indicate that humility can be perceived as a weakness of the leader if the leader does not have a sufficient power base (Wang et al. 2018).

Author Contributions: All authors contributed equally to the paper and therefore share first authorship. All authors have read and agreed to the published version of the manuscript.

Funding: This research received no external funding.

Conflicts of Interest: The authors declare no conflict of interest.

\section{References}

Ackerman, Robert A., Edward A. Witt, M. Brent Donnellan, Kali H. Trzesniewski, Richard W. Robins, and Deborah A. Kashy. 2011. What Does the Narcissistic Personality Inventory Really Measure? Assessment 18: 67-87. [CrossRef] [PubMed]

Barrick, Murray R., Michael K. Mount, and Ning Li. 2013. The Theory of Purposeful Work Behavior: The Role of Personality, Higher-Order Goals, and Job Characteristics. Academy of Management Review 38: 132-53. [CrossRef]

Bradlee, Peter M., and Robert A. Emmons. 1992. Locating Narcissism within the Interpersonal Circumplex and the Five-Factor Model. Personality and Individual Differences 13: 821-30. [CrossRef]

Brailovskaia, Julia, Hans-Werner Bierhoff, and Jürgen Margraf. 2017. How to Identify Narcissism with 13 Items? Validation of the German Narcissistic Personality Inventory-13 (G-NPI-13). Assessment. [CrossRef] [PubMed]

Briner, Rob B., David Denyer, and Denise M. Rousseau. 2009. Evidence-Based Management: Concept Cleanup Time? Academy of Management Perspectives 23: 19-32. [CrossRef]

Brislin, Richard W. 1970. Back-Translation for Cross-Cultural Research. Journal of Cross-Cultural Psychology 1: 185-216. [CrossRef]

Brouns, Tim. 2019. Big Five Personality Traits and Ethical Climate as Antecedents of Servant Leadership. Paper presented at 19th Congress of the European Association of Work and Organizational Psychology (EAWOP), Turin, Italy, May 30.

Campbell, W. Keith, Eric A. Rudich, and Constantine Sedikides. 2002. Narcissism, Self-Esteem, and the Positivity of Self-Views: Two Portraits of Self-Love. Personality and Social Psychology Bulletin 28: 358-68. [CrossRef]

Conway, James M., and Charles E. Lance. 2010. What Reviewers Should Expect from Authors Regarding Common Method Bias in Organizational Research. Journal of Business and Psychology 25: 325-34. [CrossRef] 
Eva, Nathan, Mulyadi Robin, Sen Sendjaya, Dirk van Dierendonck, and Robert C. Liden. 2019. Servant Leadership: A Systematic Review and Call for Future Research. The Leadership Quarterly 30: 111-32. [CrossRef]

Externbrink, Kai, and Christian Dormann. 2015. Führen Und Entscheiden: Evidence-Based Management. In Trends Der Psychologischen Führungsforschung. Edited by Jörg Felfe. Göttingen: Hogrefe, pp. 429-39.

Externbrink, Kai, and Moritz Keil. 2018. Narzissmus, Machiavellismus Und Psychopathie in Organisationen. Wiesbaden: Springer Fachmedien Wiesbaden. [CrossRef]

Flynn, C. Brian, James W. Smither, and Alan G. Walker. 2016. Exploring the Relationship Between Leaders' Core Self-Evaluations and Subordinates' Perceptions of Servant Leadership. Journal of Leadership E Organizational Studies 23: 260-71. [CrossRef]

Graen, George B., and Mary Uhl-Bien. 1995. Relationship-Based Approach to Leadership: Development of Leader-Member Exchange (LMX) Theory of Leadership over 25 Years: Applying a Multi-Level Multi-Domain Perspective. Management Departement Faculty Publications 6: 219-47. [CrossRef]

Greenleaf, Robert K. 1977. Servant Leadership: A Journey into the Nature of Legitimate Power and Greatness. New York: Paulist Press.

Grijalva, Emily, Peter D. Harms, Daniel A. Newman, Blaine H. Gaddis, and R. Chris Fraley. 2015. Narcissism and Leadership: A Meta-Analytic Review of Linear and Nonlinear Relationships. Personnel Psychology 68: 1-47. [CrossRef]

Haidt, Jonathan. 2003. The Moral Emotions. In Series in Affective Science. Handbook of Affective Sciences. Edited by R. J. Davidson, K. R. Scherer and H. H. Goldsmith. Oxford: Oxford University Press, pp. 852-70.

Higgs, Malcolm. 2009. The Good, the Bad and the Ugly: Leadership and Narcissism. Journal of Change Management 9: 165-78. [CrossRef]

Hoch, Julia E., William H. Bommer, James H. Dulebohn, and Dongyuan Wu. 2018. Do Ethical, Authentic, and Servant Leadership Explain Variance Above and Beyond Transformational Leadership? A Meta-Analysis. Journal of Management 44: 501-29. [CrossRef]

$\mathrm{Hu}$, Li-tze, and Peter M. Bentler. 1999. Cutoff Criteria for Fit Indexes in Covariance Structure Analysis: Conventional Criteria versus New Alternatives. Structural Equation Modeling: A Multidisciplinary Journal 6: 1-55. [CrossRef]

Hunter, Emily M., Mitchell J. Neubert, Sara Jansen Perry, L. A. Witt, Lisa M. Penney, and Evan Weinberger. 2013. Servant Leaders Inspire Servant Followers: Antecedents and Outcomes for Employees and the Organization. Leadership Quarterly 24: 316-31. [CrossRef]

Lee, Angela, and Nichelle C. Carpenter. 2018. Seeing Eye to Eye: A Meta-Analysis of Self-Other Agreement of Leadership. The Leadership Quarterly 29: 253-75. [CrossRef]

Liden, Robert C., Sandy J. Wayne, Hao Zhao, and David Henderson. 2008. Servant Leadership: Development of a Multidimensional Measure and Multi-Level Assessment. The Leadership Quarterly 19: 161-77. [CrossRef]

Liden, Robert C., Alexandra Panaccio, Jeremy D. Meuser, Jia Hu, and Sandy J. Wayne. 2014. Servant Leadership: Antecedents, Processes, and Outcomes. In The Oxford Handbook of Leadership and Organizations. Edited by David V. Day. New York: Oxford University Press, pp. 1-26.

Peterson, Suzanne J., Benjamin M. Galvin, and Donald Lange. 2012. CEO Servant Leadership: Exploring Executive Characteristics and Firm Performance. Personnel Psychology 65: 565-96. [CrossRef]

Podsakoff, Philip M., and Dennis W. Organ. 1986. Self-Reports in Organizational Research: Problems and Prospects. Journal of Management 12: 531-44. [CrossRef]

Podsakoff, Philip M., Scott B. MacKenzie, Jeong-Yeon Lee, and Nathan P. Podsakoff. 2003. Common Method Biases in Behavioral Research: A Critical Review of the Literature and Recommended Remedies. The Journal of Applied Psychology 88: 879-903. [CrossRef] [PubMed]

R Core Team. 2019. R: A Language and Environment for Statistical Computing. Vienna: R Foundation for Statistical Computing.

Resick, Christian J., Daniel S. Whitman, Steven M. Weingarden, and Nathan J. Hiller. 2009. The Bright-Side and the Dark-Side of CEO Personality: Examining Core Self-Evaluations, Narcissism, Transformational Leadership, and Strategic Influence. Journal of Applied Psychology 94: 1365-81. [CrossRef]

Rosseel, Yves. 2012. Lavaan: An R Package for Structural Equation Modeling. Journal of Statistical Software 48: 1-36. [CrossRef]

Sendjaya, Sen, James C. Sarros, and Joseph C. Santora. 2008. Defining and Measuring Servant Leadership Behaviour in Organizations. Journal of Management Studies 45: 402-24. [CrossRef] 
Sprecher, Susan, and Beverley Fehr. 2005. Compassionate Love for Close Others and Humanity. Journal of Social and Personal Relationships 22: 629-51. [CrossRef]

Underwood, Lynn G. 2008. Compassionate Love: A Framework for Research. In The Science of Compassionate Love: Theory, Research, and Applications. Edited by Beverley Fehr, Susan Sprecher and Lynn G. Underwood. Malden: Wiley-Blackwell, pp. 3-25.

Van Dierendonck, Dirk. 2011. Servant Leadership: A Review and Synthesis. Journal of Management 37: $1228-61$. [CrossRef]

Van Dierendonck, Dirk, and Inge Nuijten. 2011. The Servant Leadership Survey: Development and Validation of a Multidimensional Measure. Journal of Business and Psychology 26: 249-67. [CrossRef]

Van Dierendonck, Dirk, and Kathleen Patterson. 2015. Compassionate Love as a Cornerstone of Servant Leadership: An Integration of Previous Theorizing and Research. Journal of Business Ethics 128: 119-31. [CrossRef]

Verdorfer, Armin Pircher. 2016. Examining Mindfulness and Its Relations to Humility, Motivation to Lead, and Actual Servant Leadership Behaviors. Mindfulness 7: 950-61. [CrossRef]

Verdorfer, Armin Pircher, and Claudia Peus. 2014. The Measurement of Servant Leadership: Validation of a German Version of the Servant Leadership Survey (SLS). Zeitschrift Für Arbeits- Und Organisationspsychologie AEO 58: 1-16. [CrossRef]

Wang, Lin, Bradley P. Owens, Junchao (Jason) Li, and Lihua Shi. 2018. Exploring the Affective Impact, Boundary Conditions, and Antecedents of Leader Humility. Journal of Applied Psychology 103: 1019-38. [CrossRef] [PubMed]

Wienert, A. B. 1984. Menschenbilder als Grundlage von Führungstheorien: Erste Ergebnisse einer Empirischen Überprüfung. Zeitschrift Für Betriebswirtschaft 53: 117-23.

(C) 2020 by the authors. Licensee MDPI, Basel, Switzerland. This article is an open access article distributed under the terms and conditions of the Creative Commons Attribution (CC BY) license (http://creativecommons.org/licenses/by/4.0/). 